\title{
La doctrina del Control de Convencionalidad. Un pretendido cambio de paradigma en la región americana
}

\author{
Juan Alonso Tello Mendoza*
}

\begin{abstract}
RESUMEN
El presente artículo tiene tres propósitos en orden a contribuir con el vigente debate en torno a la doctrina del control de convencionalidad. En primer lugar, determinar su actual definición según la propia jurisprudencia de la Corte Interamericana de Derechos Humanos. En segundo lugar, presentar las consecuencias más resaltantes que, tanto en el derecho constitucional como en el derecho internacional público, supone la aceptación de esta figura en cuestión. Con ello, en tercer y último lugar, evidenciar por qué la eventual aprobación estatal de esta doctrina debe contar más que con la participación de las altas cortes nacionales, con la del Parlamento de los respectivos países de la región.
\end{abstract}

Palabras clave: control de convencionalidad, Estado de derecho, diálogo jurisprudencial, Corte Interamericana de Derechos Humanos

The doctrine of the Conventionality Control. A pretended change of paradigm in the American region

\section{Abstract}

This article has three purposes in order to contribute to the ongoing debate around the doctrine of conventionality control. First, to determine its current definition according to the own jurisprudence of the Inter-American Court of Human Rights. Secondly, to present the most relevant consequences that, both in constitutional law and in public international law, suppose the acceptance of this doctrine in question. In the third place, we intend to show why the eventual States' approval of this doctrine must take into account, preferably, the parliament participation rather than the national high courts' involvement.

Keywords: conventionality Control, Rule of Law, judicial dialogue, Inter-American Court of Human Rights

* Doctorando en Derecho Constitucional por la Universidad de Barcelona. Máster en Derechos Humanos por la Universidad de Navarra. Abogado por la Pontificia Universidad Católica del Perú. Correo electrónico: juan.tellom@ ub.edu

iD https://orcid.org/0000-0003-3329-6525 


\section{Introducción}

En continuidad con lo que hemos afirmado en nuestra publicación anterior sobre esta materia (Tello, 2015, pp. 197-220), la doctrina del control de convencionalidad supone, entre otras, una contestación de la Corte Interamericana de Derechos Humanos (en adelante, la Corte IDH), a la pregunta sobre el valor jurídico de su jurisprudencia. En síntesis, afirma que la exégesis sobre la $\mathrm{CADH}$ y otros tratados interamericanos, contenida en sus sentencias y opiniones consultivas, tiene un carácter vinculante y un efecto erga omnes en aquellos Estados que han reconocido su competencia (contenciosa o consultiva). Por ello, dirá que toda autoridad nacional, sin excepción, debe cotejar su ordenamiento y prácticas domésticas a la luz de los pronunciamientos interamericanos y, de haber contradicción, decantarse por estos últimos.

Desde entonces, se ha producido una divergente respuesta tanto al interior de las altas cortes nacionales como de la doctrina académica. El presente artículo, de acuerdo a lo que hemos indicado, busca categorizar el concepto de esta doctrina según las propias resoluciones por la Corte IDH, de modo tal que, seguidamente, podamos apreciar las consecuencias jurídicas y políticas que, advertida o inadvertidamente, se generan en el marco teórico del Estado Constitucional de Derecho y sus relaciones con el derecho internacional público.

Así las cosas, no es prioridad nuestra, en esta oportunidad, dar cuenta de los principales debates al interior de la academia o de las respuestas — favorables o críticasen torno a la construcción de esta doctrina. Tampoco intentamos valorar, por ahora, si esta figura goza o no de la fundamentación jurídica sólida y necesaria para ser aceptada. Nuevamente, buscamos solo cristalizar, de modo razonable, los efectos que se producen si aprobamos este constructo teórico tal y como la Corte IDH lo propone. Dada la evidencia a la que arribamos, un verdadero cambio de paradigma en el sistema interamericano de protección de los derechos humanos, creemos insostenible que una eventual aprobación y/o incorporación de esta doctrina no cuente con la participación del parlamento, en tanto poder representativo y deliberativo por excelencia al interior de un Estado de Derecho.

\section{1. ¿Qué es la doctrina del control de convencionalidad?}

Si consideramos, únicamente, el desarrollo explícito del control de convencionalidad por parte del colegiado de la Corte IDH, esto es, sin considerar aquellas resoluciones donde ha sido abordada solo por el voto razonado de un determinado 
juez $^{1,}$ por una mención en una cita a pie de página ${ }^{2}$ o por los alegatos de las partes, tenemos que desde el año 2006 hasta mayo de 2017 se han emitido, por lo menos, cuarenta y cinco sentencias ${ }^{3} \mathrm{Y}$ cuatro opiniones consultivas ${ }^{4}$ que, en menor o mayor grado, la plantean. Así, en fidelidad a estos progresivos aportes, una definición operativa ${ }^{5}$ señalaría que:

1 Corte IDH. Caso Brewer Carías vs. Venezuela. Voto conjunto disidente de los jueces Ventura Robles y Ferrer Mac-Gregor, párr. 63; Caso Wong Ho Wing vs. Perú. Voto disidente del juez Ferrer Mac-Gregor, apartados II.C y II.E; Caso Comunidad Campesina de Santa Bárbara vs. Perú. Voto disidente del juez Ferrer Mac-Gregor, apartados II.C y II.E.; Caso Maldonado Ordoñez vs. Guatemala. Voto razonado del juez Ferrer Mac-Gregor, párr. 40; Caso Herrera Espinoza y otros vs. Ecuador. Voto concurrente del juez Ferrer Mac-Gregor, apartados C y D; Caso Trabajadores Cesados de Petroperú y otros vs. Perú. Voto parcialmente disidente del juez Sierra Porto, párrs. 12 y 25.

2 Corte IDH. Caso Manuel Cepeda Vargas vs. Colombia, párr. 208.

3 Corte IDH. Caso Almonacid Arellano y otros vs. Chile, párr. 124; Caso Trabajadores Cesados del Congreso (Aguado Alfaro y otros) vs. Perú, párr. 128; Caso La Cantuta vs. Perú, párr. 173; Caso Boyce y otros vs. Barbados, párr. 78; Caso Heliodoro Portugal vs. Panamá, párr. 180; Caso Radilla Pacheco vs. México, párr. 339; Caso Comunidad Indígena Xákmok Kásek. vs. Paraguay, párr. 311; Caso Fernández Ortega y otros vs. México, párr. 236; Caso Rosendo Cantú y otra vs. México, párr. 219; Caso Ibsen Cárdenas e Ibsen Peña vs. Bolivia, párr. 202; Caso Vélez Loor vs. Panamá, párr. 287; Caso Gomes Lund y otros ("Guerrilha do Araguaia») vs. Brasil, párr. 176; Caso Cabrera García y Montiel Flores vs. México, párr. 225; Caso Gelman vs. Uruguay, párrs. 193, 238 y 239; Caso Chocrón vs. Venezuela, párr. 164; Caso López Mendoza vs. Venezuela, párr. 226; Caso Fontevecchia y D Amico vs. Argentina, párr. 93; Caso Atala Riffo y Niñas vs. Chile, párrs. 282-284; Caso Furlan y Familiares vs. Argentina, párrs. 303-305; Caso Masacres de Río Negro vs. Guatemala, párr. 262; Caso Masacres de El Mozote y lugares aledaños vs. El Salvador, párr. 318; Caso Gudiel Álvarez y otros ("Diario Militar») vs. Guatemala, párr. 330; Caso Masacre de Santo Domingo vs. Colombia, párr. 142; Caso Mendoza y otros vs. Argentina, párr. 221; Caso Gutiérrez y Familia vs. Argentina, párr. 168 y punto resolutivo N 10; Caso Osorio Rivera y Familiares vs. Perú, párr. 274; Caso J. vs. Perú, párr. 407; Caso Liakat Ali Alibux vs. Surinam, párr. 124; Caso Norín Catrimán y otros (Dirigentes, miembros y activista del Pueblo Indígena Mapuche) vs. Chile, párrs. 436, 461 y 464; Caso Hermanos Landaeta Mejías y otros vs. Venezuela, párr. 158; Caso de personas dominicanas y haitianas expulsadas vs. República Dominicana, párrs. 311 y 471; Caso Rochac Hernández y otros vs. El Salvador, párrs. 213 y 244; Caso Omar Humberto Maldonado Vargas vs. Chile, párr. 113; Caso López Lone y otros vs. Honduras, párr. 307; Caso Ruano Torres y otros vs. El Salvador, párr. 229; Caso Comunidad Garifuna de Punta Piedra y sus Miembros vs. Honduras, párr. 346; Caso Comunidad Garifuna Triunfo de la Cruz y sus Miembros vs. Honduras, párr. 267; Caso García Ibarra y otros vs. Ecuador, párr. 103; Caso Chinchilla Sandoval vs. Guatemala, párrs. 242, 243 y 274; Caso Tenorio Roca y otros vs. Perú, párrs. 230 y 231; Caso Trabajadores de la Hacienda Brasil Verde vs. Brasil, párr. 408; Caso Pollo Rivera y otros vs. Perú, párr. 224; Caso Miembros de la Aldea Chichupac y comunidades vecinas del Municipio de Rabinal vs. Guatemala, párr. 289; Caso Andrade Salmón vs. Bolivia, párrs. 93, 94, 100 y 102; Caso Vereda La Esperanza vs. Colombia, párr. 261.

4 Corte IDH. Derechos y garantías de niñas y niños en el contexto de la migración ylo en necesidad de protección internacional. OC-21/14, párr. 31; Corte IDH. Titularidad de derechos de las personas jurídicas en el sistema interamericano de derechos humanos. OC-22/16, párr. 26; Corte IDH. Medio ambiente y derechos humanos. OC-23/17, párr. 28; Corte IDH. Identidad de género, e igualdad y no discriminación a parejas del mismo sexo. Obligaciones estatales en relación con el cambio de nombre, la identidad de género, y los derechos derivados de un vínculo entre parejas del mismo sexo. OC-24/17, párr. 223.

5 La Corte IDH ofrece también elementos para elaborar una definición operativa del control de convencionalidad. La misma: a) Consiste en verificar la compatibilidad de las normas y demás prácticas internas con la CADH, la jurisprudencia de la Corte IDH y los demás tratados interamericanos de los cuales el Estado sea parte; b) Es una obligación que corresponde a toda autoridad pública en el ámbito de sus competencias; c) Para efectos de determinar la compatibilidad con la $\mathrm{CADH}$, no solo se debe tomar en consideración el tratado, sino que también la jurisprudencia de la Corte IDH y los demás tratados interamericanos de los cuales el Estado sea parte; d) Es un control que debe ser realizado ex oficio por toda autoridad pública; y e) Su ejecución puede implicar la supresión de normas contrarias a la $\mathrm{CADH}$ o bien su interpretación conforme a la $\mathrm{CADH}$, dependiendo de las facultades de cada autoridad pública. Corte IDH (2015). Cuadernillo de Jurisprudencia de la Corte Interamericana de Derechos Humanos. Control de 
Es deber de toda autoridad pública, en particular de los jueces y de los órganos encargados de la administración de justicia en todos sus niveles, ejercer ex officio un 'control de convencionalidad' entre, de una parte, toda norma jurídica interna —incluso las plebiscitarias 6 - y, de otra parte, la Convención Americana, los demás instrumentos interamericanos de los que el Estado es parte, así como la interpretación que de los mismos ha hecho la Corte IDH, sea por medio de su función contenciosa o consultiva. Tal deber, desenvuelto en el marco de sus respectivas competencias y regulaciones procesales correspondientes, implica la adopción de medidas en dos vertientes: i) la supresión de las normas y prácticas de cualquier naturaleza que entrañen violación a las garantías previstas en la Convención o que desconozcan los derechos allí reconocidos u obstaculicen su ejercicio, y ii) la expedición de normas y el desarrollo de prácticas conducentes — la realización de una debida interpretación conforme, por ejemplo- a la efectiva observancia de dichas garantías.

En suma, la doctrina del control de convencionalidad importa la confrontación del íntegro de normas o prácticas internas con los estándares interamericanos que, de acuerdo a la Corte IDH, estarían conformados no solo por la CADH y otros tratados interamericanos, sino también por toda interpretación que este órgano judicial haya hecho de estos. Así, de encontrarse una incompatibilidad, los estándares interamericanos —al ser vinculantes ${ }^{7}$ — deberían prevalecer. Esta tarea, además, constituiría un deber de toda autoridad nacional, lo cual configuraría una especie de «control difuso de convencionalidad»(Ferrer Mac-Gregor, 2012, pp. 133-160), mientras que si lo realizase la Corte IDH como parte de su labor inherente, tendríamos una suerte de «control concentrado o complementario de convencionalidad» (Ferrer Mac-Gregor, 2012, pp. 132-133).

De ser ejercida esta labor por parte de la autoridad nacional, la prevalencia de los estándares interamericanos podría darse por medio de la supresión de normas o

Convencionalidad, p. 6; y, Corte IDH (2017). Cuadernillo de Jurisprudencia de la Corte Interamericana de Derechos Humanos. Control de Convencionalidad, p. 9.

6 Cuando se alude a las «normas jurídicas plebiscitarias», nos referimos al recurso de referéndum y al plebiscito llevados a cabo en Uruguay (Caso Gelman, 2011), por los que la población aprobó y ratificó la Ley de Caducidad (de acuerdo a la Corte IDH, una ley de amnistía que impide la investigación y sanción de los responsables de la realización de desapariciones forzadas).

7 El carácter vinculante de las disposiciones de la $\mathrm{CADH}$ y de los demás tratados interamericanos de derechos humanos no supone mayor duda. En razón de lo anterior, de acuerdo al artículo 68.1 de la CADH, las decisiones de la Corte IDH también son vinculantes. Pero, ante una eventual incertidumbre de si la Corte IDH ha querido afirmar con la doctrina del control de convencionalidad que su jurisprudencia goza también de una naturaleza vinculante, véase una reciente ponencia del juez interamericano Ferrer Mac-Gregor en México. En ella el mencionado juez, citando la resolución de supervisión de cumplimiento de sentencia del caso Gelman vs. Uruguay, explica que para la Corte IDH, la jurisprudencia interamericana no es orientativa sino vinculante para los Estados, sean estos parte o no del proceso de la que emanó. Asimismo, no solo afirma que, según la OC-21/14, también forman parte del parámetro de convencionalidad las opiniones consultivas de la Corte IDH, sino que agrega en dicho marco a las medidas provisionales. Esto último no ha sido afirmado, al menos hasta el momento, por el colegiado de la Corte IDH. (Ferrer Mac-Gregor, 2015). 
prácticas internas que la contraríen o a través de la expedición de normas o desarrollo de prácticas que la secunden. Esta segunda modalidad, se aprecia, permitiría comprender que ante determinadas omisiones normativas de un Estado, el ejercicio del control de convencionalidad supondría suplirlas, sea mediante normas o mediante el desenvolvimiento de prácticas como, por ejemplo, una debida interpretación conforme por parte de los operadores jurídicos.

Hasta aquí, como se habrá percibido, es posible apreciar la secuencia de secuelas a producirse si los Estados americanos aceptan esta doctrina en los términos establecidos por la propia Corte IDH. En el siguiente acápite, intentaremos seńalar aquellas consecuencias que, a nuestro criterio, resultan de mayor envergadura al momento de sopesar la aprobación, matización o rechazo de esta figura teórica.

\section{Un pretendido cambio de paradigma en la región americana}

O, en términos de Sagüés (Corte IDH, 7 al 11 de octubre de 2013), «una revolución copernicana» sobre la comprensión de los derechos humanos y la constitución. Esto pues, lo adviertan o no los magistrados de la Corte IDH, de aceptarse la doctrina del control de convencionalidad tal y como la proponen, forzosamente, debemos reconocer las consecuencias que se generan tanto en el sistema interamericano de protección de los derechos humanos, como en el Estado Constitucional de Derecho o en las relaciones derecho interno-derecho internacional. Presentaremos las mutaciones más acentuadas que se producen.

\section{a) Equiparación entre la eficacia del tratado y de la jurisprudencia: un efecto dominó}

Si la Corte IDH afirma que, en aplicación de la doctrina del control de convencionalidad, las autoridades nacionales deben hacer prevalecer los estándares interamericanos por sobre las normas o prácticas internas en caso de confrontación; y, si dentro de tales estándares, considera que no solo se hayan la $\mathrm{CADH}$ y otros tratados interamericanos, sino también toda interpretación (jurisprudencia) que haya hecho sobre ellas, luego, al menos de cara a los ordenamientos jurídicos domésticos, confiere a dicha jurisprudencia el mismo grado de eficacia que detentan los tratados.

Bien es sabido que, en razón del principio pacta sunt servanda, es universalmente reconocido que todo "tratado en vigor obliga a las partes y debe ser cumplido de buena fe» (Artículo 27 de la Convención de Viena sobre el Derecho de los Tratados). Siendo así, las disposiciones de un tratado son de obligatorio cumplimiento, esto es, gozan de un carácter o naturaleza vinculante, y tienen efectos erga omnes, es decir, los efectos generales o "contra todos» de una norma. Sin embargo, al menos en la tradición del derecho continental en la que nos hallamos, no sucede así con la jurispru- 
dencia dada por un tribunal (la Corte IDH), por más que refiera a la interpretación de un tratado, en tanto sus sentencias no se rigen bajo el principio stare decisis et non quieta muovere, regla del precedente judicial de obligatorio cumplimiento propia del derecho anglosajón (Malarino, 2011, pp. 437-439).

En el mismo sentido argumentó la Suprema Corte de Justicia del Uruguay ${ }^{8}$ cuando en 2013, en respuesta a la Corte IDH, señaló que su «ordenamiento constitucional y legal no instituye un deber de las autoridades judiciales de la República Oriental del Uruguay de considerar como precedentes vinculantes los fallos de los órganos interamericanos». De allí a que nos sorprenda que el juez interamericano Ferrer Mac-Gregor, luego de citar textualmente el artículo 68.1 de la CADH, señale que ello:

[...] no puede ser limitante para que la jurisprudencia de la Corte IDH adquiera 'eficacia directa' en todos los Estados nacionales que han reconocido expresamente su jurisdicción, con independencia de que se derive de un asunto donde no han participado formalmente como 'parte material', ya que al ser la Corte IDH el único órgano jurisdiccional internacional del $[\mathrm{SIPDH}],[\ldots]$ sus interpretaciones adquieren el mismo grado de eficacia del texto convencional» (2012, pp. 159-160).

Como se aprecia, difícilmente, podríamos compartir tal opinión pues, en adición a la distinción realizada líneas arriba entre tratado y jurisprudencia, si el artículo 68.1 dispone que la obligación de cumplir con una decisión de la Corte IDH es para aquel Estado que fue parte de un proceso interamericano, a contrario sensu, los demás no se encuentran en estricto sentido vinculados ni por la decisión en sí, ni por sus fundamentos (jurisprudencia). Esto último no impide — claro está— que debido al grado de protección y al rigor persuasivo que aporte un fallo, pueda y deba ser seguido por los demás.

\section{b) Un gobierno de jueces no legitimo y la desnaturalización del principio pro homine}

Pero los inconvenientes no cesan allí. De aceptar que tanto la CADH como la jurisprudencia interamericana gozan de análoga eficacia directa, es preciso admitir también que cada sentencia dada por la Corte IDH supone una constante actualización y/o extensión de la $\mathrm{CADH}$ y otros tratados interamericanos, una "conferencia

\footnotetext{
8 Suprema Corte de Justicia del Uruguay. Caso 20/2013. Proceso de Inconstitucionalidad. Sentencia de 22 de febrero de 2013. Considerando III.a y III.b. Argumentación reiterada en sentencias posteriores, véase: Caso 87/2013. Considerando III.a y III.b; Caso 152/2013. Considerando III.a y III.b; Caso 212/2013. Considerando VII.b; Caso 217/2013. Considerando III.a y III.b; Caso 380/2013. Considerando III.a y III.b; Caso 392/2013. Considerando III.a y III.b; Caso 480/2013. Considerando III.a y III.b; Caso 506/2013. Considerando VII.b; Caso 567/2013. Considerando VII.b; Caso 83/2014. Considerando III.a y III.b; Caso 84/2014. Considerando VII.b; Caso 85/2014. Considerando III.a y III.b; Caso 86/2014. Considerando VII.b; Caso 89/2014. Considerando III.a y III.b; Caso 141/2014. Considerando VII.b; Caso 382/2014. Considerando VII.b; Caso 724/2014. Considerando III.a y III.b.
} 
internacional en sesión permanente» en palabras de Sodero (2012, p. 469), claro está, ya sin la intervención de los Estados parte. Es decir, en la práctica, considerar a las resoluciones de la Corte IDH como precedentes de obligatorio cumplimiento conlleva no solo comprender a la jurisprudencia interamericana como una permanente e inadvertida extensión de la $\mathrm{CADH}$-mediante una interpretación mutativa por adición, según Sagüés (2009, p. 82) —, sino también desplazar a los Estados de la participación en la creación de las obligaciones internacionales que han de asumir. En adelante, bastaría la intervención de los jueces de la Corte IDH, convertidos ahora en una suerte de legisladores regionales.

Podría, quizás, intentarse refutar lo aquí señalado de la siguiente manera. Según Ferrer Mac-Gregor (2012, pp. 153-154), para la Corte IDH, la vinculatoriedad de la jurisprudencia no debe ser entendida como un sinónimo de «obligatoriedad», sino de «estándar mínimo de efectividad», el cual puede ser dejado de lado si es «maximizado» o «ampliado» por una interpretación o norma (nacional o internacional), es decir, por una aplicación del principio pro homine. De ser así, podría decirse que no es verdad que los Estados han sido apartados, pues podrían participar siempre que maximicen el «estándar mínimo de efectividad» contenido en la jurisprudencia interamericana. Pero, si observamos bien, pese a la distinta terminología, los efectos prácticos son análogos. La razón: no podría desconocerse o dejarse de lado aquel patrón definido como «mínimo» o límite inferior que conforma un piso para el entendimiento de la Corte IDH y que, además, goza de la misma eficacia que tiene el tratado. En tal sentido, necesariamente, tendría que seguirse siempre la jurisprudencia interamericana: «el estándar mínimo de efectividad». Si esto es así, habría que reconocer también que la noción del principio pro homine o pro persona ya no sería la habitualmente conocida.

En efecto, bajo la tesis de Ferrer Mac-Gregor, el principio pro homine debería comprenderse como un agregado a ese piso ya establecido. En otras palabras: esto (la jurisprudencia de la Corte IDH entendida como estándar mínimo de efectividad) y más (la ampliación dada por otra interpretación o norma). El problema en esta posición es que, según la definición clásica de tal principio, si la interpretación o norma más favorable supusiese, en lugar de una complementación o adición, una oposición a lo fijado en la jurisprudencia, debería ignorarse esta última y escogerse aquella primera. Ergo, tal jurisprudencia no conformaría, forzosamente, un estándar mínimo de efectividad. De hecho, el principio pro homine:

[...] es un criterio hermenéutico que informa todo el derecho de los derechos humanos, en virtud del cual se debe acudir a la norma más amplia, o a la interpretación más extensiva, cuando se trata de reconocer derechos protegidos e, inversamente, a la norma o a la interpretación más restringida cuando se trata de establecer restric- 
ciones permanentes al ejercicio de los derechos o su suspensión extraordinaria. Este principio coincide con el rasgo fundamental del derecho de los derechos humanos, esto es, estar siempre a favor del hombre. (Pinto, 1997, p. 163) ${ }^{9}$

Por tanto, a diferencia de lo planteado por Ferrer Mac-Gregor (y, según él, de lo adoptado por la Corte IDH) un real ejercicio del principio pro homine debería permitir a un Estado optar por la interpretación o norma más favorable, incluso en desmedro de la jurisprudencia interamericana si tal fuese el caso. Señalar lo contrario supondría, por un lado, desnaturalizar el principio pro homine y, por otro lado, afirmar de modo tácito que, necesariamente, toda interpretación hecha por la Corte IDH es siempre la más protectora de los derechos humanos (la salvedad, dirá él, se dará solo cuando una norma o interpretación amplíe lo que dice la Corte IDH, nunca cuando la contraríe). Hasta donde sabemos, el don de infalibilidad no es propio de un tribunal internacional (Sodero, 2012, p. 470). Recuérdese en tal caso que, siguiendo a Daübler, sería la CADH y no la jurisprudencia interamericana la que — en estricto - establecería el "piso mínimo» exigible a los Estados signatarios, en la medida que el "propósito de los tratados internacionales es definir un estándar de derecho internacional que deben cumplir todos los países» (2012, p. 138). Incluso afirma que, de ofrecer el tratado una menor protección que la dada por la constitución nacional, debe tener supremacía esta última, caso contrario, debe prevalecer la convención. Asimismo, de preverse en distintos convenios una misma cuestión, pero sin solución unificada, no deberían verse afectados los derechos más favorables en otros tratados, «de manera que en cada caso se aplique la solución más beneficiosa para el ciudadano» (Daübler, 2012, p. 139).

\section{c) Una conocida solución jerárquica que poco soluciona}

Lo anterior es, ciertamente, complicado si además constatamos que el control de convencionalidad asume una tesis por la que el derecho internacional se superpone al derecho interno. Tal postura, empero, al igual que la del dualismo, no resulta ya útil como concepto básico. Para Von Bogdandy, en «el plano doctrinal, es más factible concebir la relación entre el derecho internacional público y el derecho interno acudiendo a las instituciones jurídicas de la interpretación conforme al derecho internacional público y del efecto directo de sus normas y obligaciones» (2012, p. 22), ambas, creaciones de derecho interno a interpretarse a la luz de principios constitucionales. De allí a que el autor asevere que el concepto general más adecuado en el derecho contemporáneo no sea el de una "pirámide», sino el de un «acoplamiento» normativo, pues responde mejor al reconocimiento de un pluralismo jurídico donde interactúan distintos ordenamientos.

\footnotetext{
9 Véase también: Amado, 2011, pp. 9-10; Amaya Villareal, 2005, pp. 350-370.
} 
Este «acoplamiento» puede realizarse tanto por medio de instituciones políticas como a través de instituciones administrativas y judiciales. Al interior de las instituciones judiciales, dirá Von Bogdandy, «el efecto interno de las normas internacionales suele derivarse de la doctrina del efecto directo y de la doctrina de la interpretación conforme» (2012, p. 27). Según él, como regla general del efecto directo, "corresponde al orden jurídico interno decidir sobre el rango y los efectos de la norma internacional dentro del territorio del Estado» (2012, p. 29). Una pretendida excepción a esta regla sería la doctrina del control de convencionalidad, que busca otorgar efecto directo a los pronunciamientos de la Corte IDH. De tener éxito la figura — dirá Von Bogdandy-, la Corte IDH dejaría de ser una institución internacional para convertirse en una institución supranacional.

Mientras tanto, las doctrinas que demarcan la relación entre el derecho interno y el internacional (la interpretación conforme $\mathrm{e}^{10} \mathrm{y}$ el efecto directo ${ }^{11}$ ) requerirían una reconceptualización. La primera, en concordancia con el enfoque del Tribunal Constitucional Federal alemán12, debería «basarse en el contexto interpretativo general de la Constitución interna», pues una aplicación mecánica del derecho internacional que no lo considere, podría afectar derechos fundamentales. La segunda, por su parte, no depende de la determinación de las disposiciones del derecho internacional. Ello en sí conforma un criterio indeterminado que, además, no hace justicia al papel «acoplador» ni a la función constitucional de esta doctrina, poniendo de relieve, más bien, que:

[...] afecta a varias cuestiones constitucionales, tales como la separación de poderes entre instituciones nacionales, el papel de las instituciones políticas, y su relación con los órganos administrativos y el poder judicial, así como la situación de sus ciudadanos en un contexto social y político globalizado. (Von Bogdandy, 2012, p. 30)

Por ello, «ambas doctrinas deben sustentarse en un equilibrio entre diversos principios constitucionales como son la cooperación internacional, por una parte, y el gobierno democrático, la subsidiariedad y la protección de los derechos fundamentales, por el otro» (Von Bogdandy, 2012, p. 30). Esto pues siempre «debería existir la posibilidad, al menos en las democracias liberales, de limitar dentro del ordenamiento interno el efecto de una norma o de una acto derivado del derecho internacional que colisione de forma grave con principios constitucionales. Ello está en consonancia con la

\footnotetext{
10 También llamada doctrina Charming Betsy, proveniente del caso Murray v. The Schooner Charming Betsy 6 U.S. (2 Cranch) 64 (1804).

11 También llamada doctrina del carácter autoejecutivo (self-executing) del derecho internacional.

12 Según Von Bogdandy (2012), con la sentencia Görgülü el «Tribunal sostuvo que la cuestión no consiste en no tener en cuenta el derecho internacional, sino en que su aplicación mecánica, sin considerar las normas de mayor jerarquía, puede vulnerar los derechos fundamentales. En todo caso, el contexto interpretativo de la Constitución Nacional tiene que ser considerado» (p. 22).
} 
evolución del derecho internacional, y con la discutida legitimidad de determinados actos jurídicos internacionales» (Von Bogdandy, 2012, p. 40).

En suma, el enfoque jerárquico que presupone la doctrina del control de convencionalidad se encontraría desfasado frente al estado actual de las relaciones entre el derecho interno y el internacional (Von Bogdandy citado por Landa, 2012, p. 30). La figura del acoplamiento normativo sería la que mejor reflejaría y explicaría la dinámica interacción entre los diversos ordenamientos que componen el «pluriverso» — por contraposición a universo- normativo o pluralismo jurídico.

\section{d) La anulación de la noción de "diálogo jurisprudencial» o "diálogo entre cortes»}

Hasta aquí, dadas las cosas, es plausible afirmar también que la habitual comprensión de diálogo jurisprudencial, judicial o entre tribunales, quedaría vaciada de contenido para convertirse más en un monólogo o diálogo unidireccional. En efecto, bajo el marco de entendimiento que traza la doctrina del control de convencionalidad, si bien la Corte IDH podría adoptar y nutrir su repertorio exegético tomando, discrecionalmente, criterios jurisprudenciales de las altas corte nacionales; en sentido inverso, estas altas cortes no podrían sino acatar, obligatoriamente, las directrices jurisprudenciales dadas por este órgano interamericano. De lo contrario, arriesgarían a sus Estados a ser internacionalmente responsables por incumplir, quizás, más que la $\mathrm{CADH}$ u otro tratado interamericano, la interpretación sobre ellos hecha por la Corte IDH. No sorprende por ello, que Thury haya afirmado en su momento:

Aquí se habla de «interacción» y de «diálogo sustantivo» pero la dirección en que ellos se producen va en un único sentido: de la CIADH a las instancias nacionales, nunca en dirección contraria. ¿QQué quiere decir ello? Que la CIADH cita con profusión a las Cortes nacionales cuando estas adoptan sus doctrinas o aceptan el CC [control de convencionalidad], pero no incorpora los desarrollos sustanciales de las instancias inferiores. Su postura, según queda ejemplificado en los dos casos analizados, sugiere que la Corte no parece dispuesta a compartir el monopolio de la interpretación convencional sino simplemente tener como unidades ejecutoras de sus estándares a los jueces nacionales. En esas condiciones, creemos, no es razonable hablar de asociación ni de una comunidad jurídica sino más bien de la imposición de una relación jerárquica, con pocas opciones para la apropiación nacional. (Thury, 2012, bloque D)

En cambio, un verdadero diálogo o 'fertilización cruzada', debe permitir la retroalimentación y reciprocidad de influjos "para enriquecer cuantitativa y cualitativamente la tutela y la realización de los derechos humanos por medio del intercambio y aprendizaje mutuos» (Bazán, 2014, p. 777), pues el asunto:

[...] ya no puede enfocarse exclusivamente a partir de una matriz unidireccional desde

la Corte IDH hacia los tribunales o cortes constitucionales y cortes supremas [...], sino que corresponde hacer foco en una 'construcción trasnacional y cooperativa de 
estándares de derechos humanos, con efectos tanto a nivel nacional como regional. (Bazán, 2014, p. 777)

\section{e) De un Estado Constitucional de Derecho a un ¿Estado Convencional de Derecho?}

Aún hay más. Haciendo una secuencia lógica desde las premisas iniciales de la doctrina del control de convencionalidad, Sagüés (Corte IDH, 7 al 11 de octubre de 2013, 1h 8' y 1h 9' 50”) se pregunta:

[...] ¿no estamos transformando la constitución nacional en una constitución convencionalizada?, ¿qué es la constitución convencionalizada? La constitución convencionalizada es la misma constitución nacional, pero una constitución depurada o desactivada cuando sus ingredientes son absolutamente incompatibles [...] con el Pacto de San José o con la jurisprudencia de la Corte Interamericana de Derechos Humanos.

Y no le falta razón. Si el control de convencionalidad concede a la jurisprudencia de la Corte IDH el mismo grado de eficacia que detentan la $\mathrm{CADH}$ y otros tratados interamericanos, por un lado, y, por otro lado, supone una solución jerárquica donde prevalece el derecho internacional por sobre el derecho interno, luego, cae por peso propio inferir que también las Constituciones nacionales de los Estados de la región están sujetas a cotejo y depuración frente al «estándar interamericano». Es decir, no solo de cara a la CADH y demás tratados, sino incluso frente a la jurisprudencia de la Corte IDH.

En la misma línea, pero llevando coherentemente el asunto hasta el final, Castillo Córdova (2015, pp. 55-62) ha manifestado que la doctrina del control de convencionalidad implicaría reconocer que no nos encontramos ya en un Estado Constitucional de Derecho, sino en un Estado Convencional de Derecho. Ello, pues la naturaleza jurídica de dicha doctrina exige, por un lado, el reconocimiento de la posición jerárquica superior de la CADH por sobre toda constitución, ley o reglamento nacional $y$, por otro lado, la consecuente validez jurídica del derecho interno toda vez que se ajuste a la $\mathrm{CADH}$. De allí a que concluya que el control de convencionalidad «es un mecanismo que determina la validez jurídica de la normativa interna de cada Estado en la medida que jerárquicamente se le coloca por debajo de la CADH» (Castillo Córdova, 2015, p. 56).

Los razonamientos hasta aquí esbozados, nos obligan a evidenciar que, bajo el marco de comprensión requerido por la doctrina del control de convencionalidad (el de una Constitución convencionalizada al interior de un Estado Convencional de Derecho), una Constitución Política puede estar, a menudo, a merced de la jurisprudencia interamericana. Esto quiere decir, sujeta a modificación cuando dicha jurisprudencia así lo determine, ya sin la necesaria participación del poder constituido deliberativo y 
representativo por excelencia (el parlamento) e ignorando los mecanismos democráticos previstos para la reforma constitucional. A todas luces, un despropósito teórico y práctico.

Esto último, no puede llevarnos sino a afirmar que, la doctrina del control de convencionalidad origina: a) un trastocamiento a la habitual separación de poderes concebida en los Estados republicanos; b) la erosión de la supremacía de la Constitución y, consecuentemente, la relativización de la teoría del Poder Constituyente; y, c) el cercenamiento de debates jurídicos contemporáneos en torno a temas de derechos humanos polémicos que, quizás, sea mejor resolver internamente antes que externamente, en razón de las diversas realidades y escalas axiológicas dentro de los países de la región.

Nos explicamos. La «crisis» de la división de poderes, como la llama Rey Cantor (2009, p. 769), se da en razón de que si el objeto del control de convencionalidad «es toda actuación de los poderes públicos de los Estados Miembros», los actos expedidos en ejercicio de las funciones constituyente, legislativa, administrativa y judicial han de ser «controlables por un órgano judicial internacional, lo que indica que el reparto de competencias, exclusivamente no está dispuesto por la Constitución, como tampoco la plena independencia de los poderes del Estado de derecho». En similar sentido, Gozaíni (2008, p. 84), si bien lee el reparo hecho por distintos tribunales supremos frente a la jurisprudencia interamericana en clave de resistencias negativas, ha dado cuenta de esta percepción compartida en cuanto al recorte de las libertades de gestión del Poder Ejecutivo y Legislativo, así como el otorgamiento de un amplio poder a la Corte IDH.

Continuando con Rey Cantor, a pesar que parece ser favorable a esta nueva figura, no deja de reconocer que también se dan dificultades en torno a la teoría del Poder Constituyente, pues si por el mismo entendemos «la competencia, capacidad o energía para constituir o dar Constitución al Estado, es decir, para organizarlo, para establecer su estructura jurídica-política» (Bidart, 1994, p. 189), hay muchas interrogantes por hacer, por ejemplo, «¿Se limitaría este poder de dar Constitución al Estado o reformarla con los fallos de la Corte Interamericana? ¿Cuáles serían los órganos que activarían la iniciativa Constituyente? ¿El constituyente primario o el secundario, o la Corte Interamericana creada por los Estados que celebraron la Convención Americana?» En suma, acierta este autor cuando asevera que no cabe duda que la jurisprudencia de la Corte IDH produce una doble erosión:

[...] al principio de la Supremacía de la Constitución y a la teoría del 'Poder' Constituyente, teniendo como fuente el pueblo 'soberano', porque es claro que no goza de 'supremacía' una Constitución que eventualmente podrá ser objeto de un Control de Convencionalidad en sede internacional frente a un tratado internacional, 
porque incorpora en la Carta Política una norma inconstitucional incompatible con el tratado [o con la propia jurisprudencia de la Corte IDH] y, por consiguiente, ese 'poder' Constituyente dejaría de ser incondicionado e ilimitado, supremo, superior y único [...]. (Rey Cantor, 2009, p. 769)

Es decir, según lo visto hasta aquí, si ya resulta discutible jurídicamente la eventual aceptación de un control que tenga como objeto a la Constitución y como parámetro al tratado — por la sumisión jerárquica y las consecuencias que supone-, resulta aún más cuestionable que dicho control pueda llegar a modificar una Carta Política —expresión máxima del poder constituyente- en razón ya no del tratado, sino de la jurisprudencia emitida por siete jueces sin legitimidad democrática, cuya función es ejercida de modo temporal, a medio tiempo y sin conocimiento pleno del ordenamiento jurídico del Estado al que cambian de Norma Superior. Esto, sin ingresar a considerar la potencial bondad o perjuicio generado por dicho cambio constitucional que, así como podría ser acertado por la protección que provee, podría también ser pernicioso si el estándar previsto en la Carta Magna es superior. Finalmente, este ámbito de discusión es posterior a la determinación de si corresponde o no al control de convencionalidad este tipo de incidencia. Para la Corte IDH es claro que sí, de allí a que se exponga el cambio de paradigma que produce esta figura jurídica.

Finalmente, también es verdad que este entendimiento del control de convencionalidad supone riesgos reales para la democracia constitucional en el marco de un Estado de Derecho. Si por democracia constitucional (Fioravanti, 2001, pp. 163-164) comprendemos ese justo equilibrio entre, de una parte, el principio democrático mediante las instituciones de la democracia política (legislativa y ejecutiva) - y, de otra parte, los límites de la política — a través de la norma constitucional y el control de constitucionalidad-, resulta imperioso admitir que dicho equilibrio ha sido resquebrajado. El respeto al principio democrático deviene en ilusorio si contemporáneos debates internos en complejos asuntos sobre derechos humanos son, fácilmente, diluidos y decididos verticalmente desde una directriz proveniente de la Corte IDH, de manera especial, cuando dicha materia no hizo parte del tratado primigenio y solo es posible abordarlo con amplias cuotas de creatividad interpretativa de carácter dinámico. Más aún, si este órgano interamericano se resiste, permanentemente, a conceder razonables márgenes de apreciación nacional a los Estados de la región. Asimismo, si la norma constitucional y el control de constitucionalidad descienden a un segundo orden debido a la norma convencional y al control de convencionalidad, habríamos mutado - inconsultamente - de una democracia constitucional a una democracia convencional, eso sí, mermándose el necesario principio democrático y hallándonos, en adelante, en un sistema —el interamericano- donde ya no existen los reales contrapesos previstos en el orden interno: el parlamento y el ejecutivo. 


\section{f) Una supra-constitución y un tribunal constitucional interamericano}

Lo narrado en el segmento anterior, nos conlleva, necesariamente, al siguiente estadio. $\mathrm{Si}$, de nuevo, existe una jerarquía del orden internacional por sobre el constitucional, si la constitución nacional se convierte en una constitución convencionalizada, esto es, reformulada por la $\mathrm{CADH}$ y la jurisprudencia interamericana, y si nos encontramos ya no en un Estado Constitucional de Derecho, sino en un Estado Convencional de Derecho; parece forzoso asentir que la $\mathrm{CADH}$, en adelante, ha de hacer las veces de una constitución latinoamericana en materia de derechos humanos, mientras la Corte IDH, su genuino intérprete, ha de cumplir el rol de tribunal constitucional interamericano.

¿Es desmesurada la proyección anticipada? De ningún modo. Este entendimiento se corrobora con lo afirmado por el entonces juez interamericano Caldas, quien ha señalado que «si a los tribunales supremos o a los constitucionales nacionales incumbe el control de constitucionalidad y la última palabra judicial en el marco interno de los Estados, a la Corte Interamericana de Derechos Humanos cabe el control de convencionalidad y la última palabra cuando el tema encierre debate sobre derechos humanos» ${ }^{13}$. Esto es así debido a que, para aquellos Estados que adoptaron la $\mathrm{CADH}$, esta equivaldría a una "constitución supranacional referente a los derechos humanos ${ }^{14}$ frente a la cual todos los poderes públicos y sus resoluciones o actos deberían adecuarse. De allí a que afirme también que «inclusive las Constituciones nacionales han de ser interpretadas o, si necesario, hasta emendadas para mantener armonía con la Convención y con la jurisprudencia de la Corte Interamericana de Derechos Humanos» ${ }^{15}$.

Lo anterior, sumado al desdibujamiento de la democracia constitucional y a un —cada vez más frecuente y flexible— método de interpretación evolutivo, haría plenamente plausible que los efectos prácticos de la doctrina del control de convencionalidad lleguen a conformar un monopolio hegemónico, por parte de la Corte IDH, de la comprensión, interpretación, extensión y contenidos de los derechos humanos en la región. De allí a que cobre sentido la advertencia de Sagüés cuando asevera que, entre las dificultades operativas de esta doctrina, tenemos que: a) constriñe la libertad interpretativa del juez nacional, atándolo a las interpretaciones que pudiesen venir desde la Corte IDH; b) supone un «sacrificio ideológico», pues antepone la ideología que anima la actuación de la Corte IDH por sobre el techo ideológico que campea en una Constitución local al momento de interpretar de una regla constitucional;

\footnotetext{
${ }^{13}$ Corte IDH. Caso Gomes Lund y otros ("Guerrilha do Araguaia») vs. Brasil. Voto razonado del juez Caldas, párr. 4.

${ }^{14}$ Corte IDH. Caso Gomes Lund y otros ("Guerrilha do Araguaia”) vs. Brasil. Voto razonado del juez Caldas, párr. 5.

15 Corte IDH. Caso Gomes Lund y otros ("Guerrilha do Araguaia») vs. Brasil. Voto razonado del juez Caldas, párr. 6.
} 
y, c) «encadena» a los Estados que no fueron parte de una controversia, y que, por tanto, no fueron escuchados ni pudieron aportar su opinión respecto a una tesis jurisdiccional determinada, trastocándose así las habituales reglas del debido proceso (Sagüés, 2010, p. 5).

\section{Una reflexión final}

Frente a ello, tres preguntas: ¿esta configuración corresponde a la voluntad originaria de los Estados al conformar el sistema interamericano de protección de los derechos humanos? Independientemente de ello, de ser el caso, ¿no deberían intervenir los Estados en una transformación de esta envergadura? O, siguiendo a Alpizar y Bello (Romero, 2011, p. 27), ¿no deberíamos incluir una cláusula especial en la $\mathrm{CADH}$ en orden a que los Estados partes acepten, libre y voluntariamente, otorgar un efecto vinculante a las resoluciones judiciales de la Corte IDH (el primer peldaño que produce, seguidamente, el efecto dominó)? Por último y más importante, ¿existe fundamentación jurídica sólida y suficiente para sostener desde la Corte IDH esta figura teórica?

Vayamos en orden y de modo conciso. En cuanto a la primera pregunta, la historia no permite sino afirmar que el nuevo paradigma que pretende crear la Corte IDH teniendo como herramienta a la doctrina del control de convencionalidad, resulta ajeno al sistema interamericano creado por los Estados de la región. Respecto al segundo interrogante, en efecto, la trascendencia de las mutaciones trazadas, no solo hace indiscutible la anuencia de los Estados, sino además y de modo particular, la participación del parlamento nacional de cada país, con los respectivos debates y/o consultas a la población que reclame esta "revolución copernicana», en palabras de Sagüés (2013, 50’ 50”). Esto pues, no es imaginable que, para cambios de tan grande calado constitucional e internacional, baste la incorporación de la mentada doctrina mediante una o varias sentencias de un tribunal constitucional o corte suprema justicia, sin duda órganos de suma importancia en la configuración de un Estado Constitucional de Derecho, pero ausente de la legitimidad democrática y representatividad que sí detenta un parlamento. En relación a la tercera cuestión, dicho asunto de crucial relevancia lo abordaremos en una próxima publicación, en tanto ahora nuestro propósito es distinto.

\section{Conclusión}

De acuerdo con los propósitos trazados, hemos presentado la definición de la doctrina del control de convencionalidad a partir de las resoluciones dadas por la Corte IDH 
y en fidelidad a sus propios términos. Así, podemos señalar que, mediante esta doctrina, la Corte IDH afirma que la exégesis sobre la CADH y otros tratados interamericanos, contenida en sus sentencias y opiniones consultivas, tiene un carácter vinculante y un efecto erga omnes en aquellos Estados que han reconocido su competencia (contenciosa o consultiva). En razón de ello, dirá que toda autoridad nacional, sin excepción, debe cotejar su ordenamiento y prácticas domésticas a la luz de los pronunciamientos interamericanos y, de haber contradicción, decantarse por estos últimos. De no ser así, podría generarse la responsabilidad internacional del respectivo Estado.

Seguidamente, hemos realizado un recuento de las consecuencias teórico-prácticas más notorias que esta figura supone, al menos, para el Estado Constitucional de Derecho, el sistema interamericano de protección de los derechos humanos y las relaciones derecho interno-derecho internacional vigentes. En muy sucinta síntesis, hemos narrado cómo la pretendida equiparación entre el grado de eficacia de la $\mathrm{CADH}$ y la jurisprudencia interamericana, así como la solución jerárquica que asume esta doctrina, genera, entre otros, la desnaturalización del principio pro homine y la anulación de la noción de diálogo jurisprudencial. Asimismo, hemos buscado demostrar que si somos coherentes hasta el final con los planteamientos de esta figura, debemos aceptar también que no solo carecemos ya de una Constitución nacional - convertida ahora en una Constitución convencionalizada - o de un Estado Constitucional de Derecho - transformado, en adelante, en un Estado Convencional de Derecho—, sino que, además, la $\mathrm{CADH}$ ha mutado a una especie de supra-constitución latinoamericana y que la Corte IDH conforma hoy un tribunal constitucional interamericano en materia de derechos humanos. En suma, hemos transitado, advertida o inadvertidamente, a un sistema de gobierno por parte los jueces interamericanos $\mathrm{y}$, con ello, a un profundo - e inconsulto- cambio de paradigma en la región americana. Lo anterior, claro está, si los Estados lo siguen permitiendo.

Por tal razón, luego de enlistar — sin pretensión exhaustiva - las consecuencias que, por honestidad académica, deberíamos reconocer si aceptamos la doctrina del control de convencionalidad en los términos ofrecidos por la propia Corte IDH; hemos intentado esbozar cómo es verdad que, de ser el caso, la incorporación y/o aceptación de dicha doctrina por parte de los Estados americanos, debe pasar, necesariamente, por una decisión adoptada en sede parlamentaria y/o bajo un mecanismo plebiscitario, más no solo mediante resolución tomada en sede judicial o bajo el amparo de una corte constitucional. 


\section{Referencias bibliográficas}

\section{a) Libros, revistas y ponencias}

Amado, A. (2011). El influjo del sistema interamericano de derechos humanos en las Américas y en la jurisprudencia constitucional del Perú. Revista Jurídica de Derecho Público, 6, 43-58. Recuperado de https://www.revistajuridicaonline.com/2011/12/ el-influjo-del-sistema-interamericano-de-derechos-humanos-en-las-amricas/

Amaya Villareal, A. (2005). El principio pro homine: interpretación extensiva vs. El consentimiento del Estado. International Law: Revista Colombiana de Derecho Internacional, 3(5), 337-380. Recuperado a partir de https://revistas.javeriana.edu.co/index.php/ internationallaw/article/view/14087

Bazán, V. (2014). Control de convencionalidad, tribunales internos y protección de los derechos fundamentales. Revista Jurídica Argentina La Ley, 2014-A, sección Doctrina.

Bidart, G. (1994). Tratado elemental de Derecho Constitucional Argentino. Buenos Aires: Editorial EDIAR.

Castillo Córdova, L. (2015). ¿Estado convencional de derecho? Un breve estudio sobre el control de convencionalidad. En S. Mosquera (coord.), La constitucionalización de los tratados de derechos humanos en el Perú (pp. 45-64). Lima: Universidad de Lima / Palestra Editores.

Daübler, W. (2012). Los derechos fundamentales en ordenamientos jurídicos de niveles múltiples (local, nacional, internacional, supranacional). En G. Capaldo, L. Clérico, y J. Sieckmann (dirs.), Internacionalización del Derecho Constitucional, constitucionalización del Derecho Internacional (pp. 131-143). Buenos Aires: EUDEBA.

Ferrer Mac-Gregor, E. (2012). Interpretación conformey Control Difuso de Convencionalidad. El nuevo paradigma para el juez mexicano. En E. Ferrer Mac-Gregor (coord.), El Control Difuso de Convencionalidad. Diálogo de la Corte Interamericana de Derechos Humanos y los Jueces Nacionales (pp. 107-186). México: FUNDAp.

Ferrer Mac-Gregor, E. (junio de 2015). Control de Convencionalidad y Jurisprudencia de la Corte Interamericana de Derechos Humanos. En Coloquio Regional Centro 'Casos relevantes en materia de Transparencia, Acceso a la Información Pública y Protección de Datos Personales'. Coloquio organizado por el Instituto Nacional de Transparencia, Acceso a la Información y Protección de Datos Personales - INAI, Ciudad de México, México. Recuperado de https://www.youtube.com/watch?v=ckLsQAvRLa8 (58' 55” al 1 h 3' 25")

Fioravanti, M. (2001). Constitución: de la antigüedad a nuestros días. Madrid: Trotta.

Gozaíni, O. (2008). El impacto de la jurisprudencia del sistema interamericano en el derecho interno. En S. Albanese (coord.), El control de convencionalidad (pp. 81-112). Buenos Aires: Ediar.

Landa, César (2012). Jurisdicción constitucional y jurisdicción internacional: cooperación, conflictos y tensiones. En G. Capaldo, L. Clérico, y J. Sieckmann (dirs.), Internacionalización del Derecho Constitucional, constitucionalización del Derecho Internacional (pp. 437-449). Buenos Aires: EUDEBA. 
Malarino, E. (2011). Acerca de la pretendida obligatoriedad de la jurisprudencia de los órganos interamericanos de protección de Derechos Humanos para los Tribunales Nacionales. En Grupo de Estudios sobre Derecho Penal Internacional (coord.), Sistema Interamericano de Protección de los Derechos Humanos y Derecho Penal Internacional (pp. 435-455). Montevideo: Fundación Konrad Adenauer (KAS).

Pinto, M. (1997). El principio pro homine. Criterios de hermenéutica y pautas para la regulación de los derechos humanos. En M. Abregu (coord.), La aplicación de los tratados de derechos humanos por los tribunales locales. Buenos Aires: Editores del Puerto.

Rey Cantor, E. (2009). Jurisdicción constitucional y control de convencionalidad de las leyes. En Instituto Iberoamericano de Derecho Constitucional, Asociación Peruana de Derecho Constitucional, Instituto de Investigaciones Jurídicas y Maestría en Derecho Constitucional PUCP (coords.), Memoria del X Congreso Iberoamericano de Derecho Constitucional (pp. 763-800). Lima: IDEMSA.

Romero, X. (2011). Vinculación de las resoluciones judiciales de la Corte Interamericana. Bogotá: Universidad Externado de Colombia.

Sagüés, N. (2009). El 'Control de Convencionalidad', en particular sobre las constituciones nacionales. Revista Jurídica del Perú, 104, 79-86.

Sagüés, N. (2010). Dificultades operativas del 'control de convencionalidad' en el sistema interamericano. Revista Jurídica Argentina La Ley -D, 1245, Buenos Aires.

Sagüés, N. (2013). Diálogo jurisprudencial e impacto de las sentencias de la Corte Interamericana de Derechos Humanos. Seminario Internacional realizado en el marco del $48^{\circ}$ Período Extraordinario de Sesiones, dado entre el 7 y 11 de octubre de 2013. Ciudad de México, Estados Unidos Mexicanos. Recuperado de https:/vimeo.com/album/2565106/ video/76720365 (50' al 1h 13'26”)

Sodero, E. (2012). Precedente e internacionalización del derecho constitucional. En G. Capaldo, L. Clérico, y J. Sieckmann (dirs.), Internacionalización del Derecho Constitucional, constitucionalización del Derecho Internacional (pp. 451-471). Buenos Aires: Eudeba.

Tello, J. (2015). La doctrina del control de convencionalidad: dificultades inherentes y criterios razonables para su aplicabilidad. Prudentia Iuris, 80, 197-220. Recuperado de http://bibliotecadigital.uca.edu.ar/repositorio/revistas/doctrina-control-convencionalidad-tello.pdf

Thury, V. (2012). La revisión del control de convencionalidad difuso y la identidad institucional de la Corte Interamericana de Derechos Humanos. Ponencia presentada en las Jornadas Argentino-Chileno-Peruano-Uruguayas de Derecho Constitucional, Montevideo, Uruguay, 14 y 15 de octubre de 2011.

Von Bogdandy, A. (2012). Del paradigma de la soberanía al paradigma del pluralismo normativo. Una nueva perspectiva (mirada) de la relación entre el derecho internacional y los ordenamientos jurídicos nacionales. En G. Capaldo, L. Clérico, y J. Sieckmann (dirs.), Internacionalización del Derecho Constitucional, constitucionalización del Derecho Internacional (pp. 21-40). Buenos Aires: Eudeba. 


\section{b) Sentencias de la Corte IDH}

Corte IDH. Caso Almonacid Arellano y otros vs. Chile. Excepciones Preliminares, Fondo, Reparaciones y Costas. Sentencia de 26 de septiembre de 2006. Serie C No. 154.

Corte IDH. Caso Trabajadores Cesados del Congreso (Aguado Alfaro y otros) vs. Perú. Excepciones Preliminares, Fondo, Reparaciones y Costas. Sentencia de 24 de Noviembre de 2006. Serie C No. 158.

Corte IDH. Caso La Cantuta vs. Perú. Fondo, Reparaciones y Costas. Sentencia de 29 de noviembre de 2006. Serie C No. 162.

Corte IDH. Caso Boyce y otros vs. Barbados. Excepción Preliminar, Fondo, Reparaciones y Costas. Sentencia de 20 de noviembre de 2007. Serie C No. 169.

Corte IDH. Caso Heliodoro Portugal vs. Panamá. Excepciones Preliminares, Fondo, Reparaciones y Costas. Sentencia de 12 de agosto de 2008. Serie C No. 186.

Corte IDH. Caso Radilla Pacheco vs. México. Excepciones Preliminares, Fondo, Reparaciones y Costas. Sentencia de 23 de Noviembre de 2009. Serie C No. 209.

Caso Manuel Cepeda Vargas vs. Colombia. Excepciones Preliminares, Fondo, Reparaciones y Costas. Sentencia de 26 de mayo de 2010. Serie C No. 213.

Corte IDH. Caso Comunidad Indígena Xákmok Kásek. vs. Paraguay. Fondo, Reparaciones y Costas. Sentencia de 24 de agosto de 2010. Serie C No. 214.

Corte IDH. Caso Fernández Ortega y otros. vs. México. Excepción Preliminar, Fondo, Reparaciones y Costas. Sentencia de 30 de agosto de 2010 Serie C No. 215.

Corte IDH. Caso Rosendo Cantú y otra vs. México. Excepción Preliminar, Fondo, Reparaciones y Costas. Sentencia de 31 de agosto de 2010 Serie C No. 216.

Corte IDH. Caso Ibsen Cárdenas e Ibsen Peña vs. Bolivia. Fondo, Reparaciones y Costas. Sentencia de 1 de septiembre de 2010 Serie C No. 217.

Corte IDH. Caso Vélez Loor vs. Panamá. Excepciones Preliminares, Fondo, Reparaciones y Costas. Sentencia de 23 de noviembre de 2010 Serie C No. 218.

Corte IDH. Caso Gomes Lund y otros ("Guerrilha do Araguaia") vs. Brasil. Excepciones Preliminares, Fondo, Reparaciones y Costas. Sentencia de 24 de noviembre de 2010. Serie C No. 219.

Corte IDH. Caso Cabrera García y Montiel Flores vs. México. Excepción Preliminar, Fondo, Reparaciones y Costas. Sentencia de 26 de noviembre de 2010 Serie C No. 220.

Corte IDH. Caso Gelman vs. Uruguay. Fondo y Reparaciones. Sentencia de 24 de febrero de 2011 Serie C No.221.

Corte IDH. Caso Chocrón Chocrón vs. Venezuela. Excepción Preliminar, Fondo, Reparaciones y Costas. Sentencia de 1 de julio de 2011. Serie C No. 227.

Corte IDH. Caso López Mendoza vs. Venezuela. Fondo Reparaciones y Costas. Sentencia de 1 de septiembre de 2011 Serie C No. 233.

Corte IDH. Caso Fontevecchia y D'Amico vs. Argentina. Fondo, Reparaciones y Costas. Sentencia de 29 de noviembre de 2011. Serie C No. 238. 
Corte IDH. Caso Atala Riffo y Niñas vs. Chile. Fondo, Reparaciones y Costas. Sentencia del 24 de febrero de 2012. Serie C No. 239.

Corte IDH. Caso Furlan y Familiares vs. Argentina. Excepciones Preliminares, Fondo, Reparaciones y Costas. Sentencia de 31 de agosto de 2012. Serie C No. 246.

Corte IDH. Caso Masacres de Río Negro vs. Guatemala. Excepción Preliminar, Fondo, Reparaciones y Costas. Sentencia de 4 de septiembre de 2012 Serie C No. 250.

Corte IDH. Caso Masacres de El Mozote y lugares aledaños vs. El Salvador. Fondo, Reparaciones y Costas. Sentencia de 25 de octubre de 2012 Serie C No. 252.

Corte IDH. Caso Gudiel Álvarez y otros ("Diario Militar») vs. Guatemala. Fondo Reparaciones y Costas. Sentencia de 20 noviembre de 2012 Serie C No. 253.

Corte IDH. Caso Masacre de Santo Domingo vs. Colombia. Excepciones Preliminares, Fondo y Reparaciones. Sentencia de 30 de noviembre de 2012. Serie C No. 259.

Corte IDH. Caso Mendoza y otros vs. Argentina. Excepciones Preliminares, Fondo y Reparaciones. Sentencia de 14 de mayo de 2013 Serie C No. 260.

Corte IDH. Caso Gutiérrez y Familia vs. Argentina. Fondo, Reparaciones y Costas. Sentencia de 25 de noviembre de 2013. Serie C No. 271.

Corte IDH. Caso Osorio Rivera y Familiares vs. Perú. Excepciones Preliminares, Fondo, Reparaciones y Costas. Sentencia de 26 de noviembre de 2013. Serie C No. 274.

Corte IDH. Caso J. vs. Perú. Excepción Preliminar, Fondo, Reparaciones y Costas. Sentencia de 27 de noviembre de 2013. Serie C No. 275.

Corte IDH. Caso Liakat Ali Alibux vs. Surinam. Excepciones Preliminares, Fondo, Reparaciones y Costas. Sentencia de 30 de enero de 2014. Serie C No. 276.

Corte IDH. Caso Brewer Carías vs. Venezuela. Excepciones Preliminares. Sentencia de 26 de mayo de 2014. Serie C No. 278. Voto conjunto disidente de los jueces Ventura Robles y Ferrer Mac-Gregor.

Corte IDH. Caso Norín Catrimán y otros (Dirigentes, miembros y activista del Pueblo Indígena Mapuche) vs. Chile. Fondo, Reparaciones y Costas. Sentencia de 29 de mayo de 2014. Serie C No. 279.

Corte IDH. Caso Hermanos Landaeta Mejías y otros vs. Venezuela. Excepciones Preliminares, Fondo, Reparaciones y Costas. Sentencia de 27 de agosto de 2014. Serie C No. 281.

Corte IDH. Caso de personas dominicanas y haitianas expulsadas vs. República Dominicana. Excepciones Preliminares, Fondo, Reparaciones y Costas. Sentencia de 28 de agosto de 2014. Serie C No. 282.

Corte IDH. Caso Rochac Hernández y otros vs. El Salvador. Fondo, Reparaciones y Costas. Sentencia de 14 de octubre de 2014. Serie C No. 285.

Corte IDH. Caso Wong Ho Wing vs. Perú. Excepción Preliminar, Fondo, Reparaciones y Costas. Sentencia de 30 de junio de 2015. Serie C No. 297. Voto disidente del juez Ferrer Mac-Gregor, apartados II.C y II.E

Corte IDH. Caso Comunidad Campesina de Santa Bárbara vs. Perú. Excepciones Preliminares, Fondo, Reparaciones y Costas. Sentencia de 1 de septiembre de 2015. Serie C No. 299. Voto disidente del juez Ferrer Mac-Gregor, apartados II.C y II.E. 
Corte IDH. Caso Omar Humberto Maldonado Vargas vs. Chile. Fondo, Reparaciones y Costas. Sentencia de 2 de septiembre de 2015. Serie C No. 300.

Corte IDH. Caso López Lone y otros vs. Honduras. Excepción Preliminar, Fondo Reparaciones y Costas. Sentencia de 5 de octubre de 2015. Serie C No. 302.

Corte IDH. Caso Ruano Torres y otros vs. El Salvador. Fondo, Reparaciones y Costas. Sentencia de 05 de octubre de 2015. Serie C No. 303.

Corte IDH. Caso Comunidad Garifuna de Punta Piedra y sus Miembros vs. Honduras. Excepciones Preliminares, Fondo, Reparaciones y Costas. Sentencia de 08 de octubre de 2015. Serie C No. 304.

Corte IDH. Caso Comunidad Garifuna Triunfo de la Cruzy sus Miembros vs. Honduras. Fondo, Reparaciones y Costas. Sentencia de 08 de octubre de 2015. Serie C No. 305.

Corte IDH. Caso García Ibarra y otros vs. Ecuador. Excepciones Preliminares, Fondo, Reparaciones y Costas. Sentencia de 17 de noviembre de 2015. Serie C No. 306.

Corte IDH. Caso Maldonado Ordoñez vs. Guatemala. Excepción Preliminar, Fondo, Reparaciones y Costas. Sentencia de 3 de mayo de 2016. Serie C No. 311. Voto razonado del juez Ferrer Mac-Gregor, párr. 40.

Corte IDH. Caso Chinchilla Sandoval vs. Guatemala. Excepción Preliminar, Fondo, Reparaciones y Costas. Sentencia de 29 de febrero de 2016. Serie C No. 312.

Corte IDH. Caso Tenorio Roca y otros vs. Perú. Excepciones Preliminares, Fondo, Reparaciones y Costas. Sentencia de 22 de junio de 2016. Serie C No. 314.

Corte IDH. Caso Herrera Espinoza y otros vs. Ecuador. Excepciones Preliminares, Fondo, Reparaciones y Costas. Sentencia de 1 de septiembre de 2016. Serie C No. 316. Voto concurrente del juez Ferrer Mac-Gregor, apartados $C$ y D.

Corte IDH. Caso Trabajadores de la Hacienda Brasil Verde vs. Brasil. Excepciones Preliminares, Fondo, Reparaciones y Costas. Sentencia de 20 de octubre de 2016. Serie C No. 318.

Corte IDH. Caso Pollo Rivera y otros vs. Perú. Fondo, Reparaciones y Costas. Sentencia de 21 de octubre de 2016. Serie C No. 319.

Corte IDH. Caso Miembros de la Aldea Chichupac y comunidades vecinas del Municipio de Rabinal vs. Guatemala. Excepciones Preliminares, Fondo, Reparaciones y Costas. Sentencia de 30 de noviembre de 2016. Serie C No. 328.

Corte IDH. Caso Andrade Salmón vs. Bolivia. Fondo, Reparaciones y Costas. Sentencia de 1 de diciembre de 2016. Serie C No. 330.

Corte IDH. Caso Vereda La Esperanza vs. Colombia. Excepciones Preliminares, Fondo, Reparaciones y Costas. Sentencia de 31 de agosto de 2017. Serie C No. 341.

Corte IDH. Caso Trabajadores Cesados de Petroperú y otros vs. Perú. Excepciones Preliminares, Fondo, Reparaciones y Costas. Sentencia de 23 de noviembre 2017. Serie C No. 344.

\section{c) Opiniones consultivas de la Corte IDH}

Corte IDH. Derechos y garantías de niñas y niños en el contexto de la migración y/o en necesidad de protección internacional. Opinión Consultiva OC-21/14 de 19 de agosto de 2014. Serie A No. 21. 
Corte IDH. Titularidad de derechos de las personas jurídicas en el sistema interamericano de derechos humanos (Interpretación y alcance del artículo 1.2, en relación con los artículos 1.1, 8, 11.2, 13, 16, 21, 24, 25, 29, 30, 44, 46, y 62.3 de la Convención Americana sobre Derechos Humanos, así como del artículo 8.1 A y B del Protocolo de San Salvador). Opinión Consultiva OC-22/16 de 26 de febrero de 2016. Serie A No. 22.

Corte IDH. Medio ambiente y derechos humanos (obligaciones estatales en relación con el medio ambiente en el marco de la protección y garantía de los derechos a la vida y a la integridad personal - interpretación y alcance de los artículos 4.1 y 5.1, en relación con los artículos 1.1 y 2 de la Convención Americana sobre Derechos Humanos). Opinión Consultiva OC-23/17 de 15 de noviembre de 2017. Serie A No. 23.

Corte IDH. Identidad de género, e igualdad y no discriminación a parejas del mismo sexo. Obligaciones estatales en relación con el cambio de nombre, la identidad de género, y los derechos derivados de un vínculo entre parejas del mismo sexo (interpretación y alcance de los artículos 1.1, 3, 7, 11.2, 13, 17, 18 y 24, en relación con el artículo 1 de la Convención Americana sobre Derechos Humanos). Opinión Consultiva OC-24/17 de 24 de noviembre de 2017. Serie A No. 24.

\section{d) Resoluciones, publicaciones y seminarios de la Corte IDH}

Corte IDH. Caso Gelman vs. Uruguay. Supervisión de Cumplimiento de Sentencia. Resolución de la Corte Interamericana de Derechos Humanos 20 de marzo de 2013.

Corte IDH (2013). "Diálogo jurisprudencial e impacto de las sentencias de la Corte Interamericana de Derechos Humanos". Seminario Internacional realizado en el marco del $48^{\circ}$ Periodo Extraordinario de Sesiones, dado entre el 7 y 11 de octubre de 2013. México D.F.

Corte IDH (2015). Cuadernillo de Jurisprudencia de la Corte Interamericana de Derechos Humanos. $N^{\circ}$ 7. Control de Convencionalidad.

Corte IDH (2017). Cuadernillo de Jurisprudencia de la Corte Interamericana de Derechos Humanos. $N^{\circ}$ 7. Control de Convencionalidad (versión actualizada).

\section{e) Suprema Corte de Justicia del Uruguay}

Caso 365/2009. Proceso de Inconstitucionalidad. Sentencia de 19 de octubre de 2009. Considerando III.8.

Caso 20/2013. Proceso de Inconstitucionalidad. Sentencia de 22 de febrero de 2013. Considerando III. a y III.b.

Caso 87/2013. Proceso de Inconstitucionalidad. Sentencia de 8 de marzo de 2013. Considerando III. a y III.b.

Caso 152/2013. Proceso de Inconstitucionalidad. Sentencia de 11 de marzo de 2013. Considerando VII.b.

Caso 186/2013. Proceso de Inconstitucionalidad. Sentencia de 13 de marzo de 2013. Considerando III. a y III.b.

Caso 187/2013. Proceso de Inconstitucionalidad. Sentencia de 13 de marzo de 2013. Considerando III. a y III.b. 
Caso 212/2013. Proceso de Inconstitucionalidad. Sentencia de 8 de abril de 2013. Considerando VII.b.

Caso 217/2013. Proceso de Inconstitucionalidad. Sentencia de 8 de abril de 2013. Considerando III. a y III.b.

Caso 380/2013. Proceso de Inconstitucionalidad. Sentencia de 14 de agosto de 2013. Considerando III. a y III.b.

Caso 392/2013. Proceso de Inconstitucionalidad. Sentencia de 19 de agosto de 2013. Considerando III. a y III.b.

Caso 480/2013. Proceso de Inconstitucionalidad. Sentencia de 14 de octubre de 2013. Considerando III. a y III.b.

Caso 506/2013. Proceso de Inconstitucionalidad. Sentencia de 30 de octubre de 2013. Considerando VII.b.

Caso 567/2013. Proceso de Inconstitucionalidad. Sentencia de 25 de noviembre de 2013. Considerando VII.b.

Caso 65/2014. Proceso de Inconstitucionalidad. Sentencia de 17 de marzo de 2014. Considerando 4. Caso 83/2014. Proceso de Inconstitucionalidad. Sentencia de 17 de marzo de 2014. Considerando III.a y III.b.

Caso 84/2014. Proceso de Inconstitucionalidad. Sentencia de 17 de marzo de 2014. Considerando VII.b.

Caso 85/2014. Proceso de Inconstitucionalidad. Sentencia de 17 de marzo de 2014. Considerando III.a y III.b.

Caso 86/2014. Proceso de Inconstitucionalidad. Sentencia de 17 de marzo de 2014. Considerando VII.b.

Caso 89/2014. Proceso de Inconstitucionalidad. Sentencia de 17 de marzo de 2014. Considerando III. a y III.b.

Caso 141/2014. Proceso de Inconstitucionalidad. Sentencia de 24 de marzo de 2014. Considerando VII.b.

Caso 382/2014. Proceso de Inconstitucionalidad. Sentencia de 7 de abril de 2014. Considerando VII.b.

Caso 516/2014. Proceso de Inconstitucionalidad. Sentencia de 28 de mayo de 2014. Considerando 5. Caso 527/2014. Proceso de Inconstitucionalidad. Sentencia de 2 de junio de 2014. Considerando 5. Caso 699/2014. Proceso de Inconstitucionalidad. Sentencia de 16 de julio de 2014. Considerando 5. Caso 724/2014. Proceso de Inconstitucionalidad. Sentencia de 30 de julio de 2014. Considerando III. a y III.b.

Caso 783/2014. Proceso de Inconstitucionalidad. Sentencia de 3 de septiembre de 2014. Considerando 5.

Caso 133/2015. Proceso de Inconstitucionalidad. Sentencia de 20 de mayo de 2015. Considerando IV.

Recibido: 9 de abril de 2019 Aprobado: 14 de julio de 2019 